\title{
Risk of Alzheimer's Disease in Relation to Diabetes: A Population-Based Cohort Study
}

\author{
Kai-Chen Wang ${ }^{a, b}$ Lin-Chung Woung ${ }^{c, d}$ Ming-Tsu Tsai ${ }^{e, f}$ Chih-Ching Liu ${ }^{g}$ \\ Ying-Hwa Su ${ }^{\text {h }}$ Chung-Yi Li, ${ }^{\mathrm{i}, \mathrm{j}}$ \\ aDepartment of Neurology, Cheng-Hsin General Hospital, ${ }^{b}$ Graduate Institute of Medical Sciences, National \\ Defense Medical Center, 'Department of Ophthalmology, Taipei City Hospital, d Department of Ophthalmology, \\ National Taiwan University Hospital, ${ }^{e}$ Department of Nursing, New Taipei County Hospital, ${ }^{f}$ Department of \\ Nursing, Oriental Institute of Technology, and ${ }^{9}$ Bureau of Health Promotion, Department of Health, Taipei, \\ hDepartment of Nursing, and 'Department and Institute of Public Health, College of Medicine, National Cheng \\ Kung University, Tainan, and 'Department of Public Health, College of Public Health, China Medical University, \\ Taichung, Taiwan, ROC
}

\section{Key Words}

Diabetes · Alzheimer's disease $\cdot$ Cohort studies $\cdot$ Cox proportional hazards model $\cdot$ Risk factors $\cdot$ Incidence

\begin{abstract}
Background/Aims: Detailed information on the age- and sex-specific relationships between diabetes and Alzheimer's disease (AD) is scarce. This study aims to prospectively investigate the age- and sex-specific incidence density and relative hazards of AD in relation to diabetes. Methods: A total of 615,529 diabetic patients and 614,871 age- and sexmatched random controls were linked to the claim data from 2000-2008 to identify the first occurrence of a primary or secondary diagnosis of AD. Incidence density was calculated under the Poisson assumption. We also assessed the ageand sex-specific risk of $A D$ in relation to diabetes with the Cox proportional hazards regression model. Results: Over nearly 9 years of follow-up, a total of 4,615 diabetic subjects developed $A D$, representing a cumulative incidence rate of $0.75 \%$ ( $n=3,873 ; 0.63 \%$ in controls). The overall incidence densities of $A D$ for diabetic men and women, respectively,
\end{abstract}

\section{KARGER}

Fax +4161306 1234

E-Mail karger@karger.ch

www.karger.com
(C) 2012 S. Karger AG, Basel

$0251-5350 / 12 / 0384-0237 \$ 38.00 / 0$

Accessible online at:

www.karger.com/ned were 0.82 and 1.15 per 1,000 person-years, which were higher than those for control men and women $(0.63$ and 0.89 per 1,000 person-years, respectively). Diabetic patients had a significantly higher hazard ratio (HR) of AD $[1.45,95 \%$ confidence interval $(\mathrm{Cl}) 1.38-1.52]$. Diabetic women $\geq 65$ years had a higher HR $(1.52,95 \% \mathrm{Cl} 1.42-1.62)$ than diabetic women $<65$ years (1.34, 95\% Cl 1.15-1.56). Conclusion: Diabetes may increase the risk of $A D$ in both sexes and in all ages. A higher $H R$ of $A D$ was especially notable in older diabetic women.

Copyright $\odot 2012$ S. Karger AG, Basel

\section{Introduction}

Alzheimer's disease (AD) is a devastating progressive neurodegenerative disease affecting more than 15 million people worldwide [1]. AD is characterized by neuronal loss associated with a progressive decline in memory and other cognitive functions, resulting in dementia.

K.-C.W. and L.-C.W contributed equally to this work. 
Clinically, AD is diagnosed according to the criteria from the Diagnostic and Statistical Manual of Mental Disorders, Fourth Edition [2].

Diabetes mellitus is characterized by hyperglycemia and is associated with pathological changes in numerous peripheral organs, such as the eyes, kidneys and peripheral nerves. In addition, diabetes affects the central nervous system. Learning disability and memory deficits are observed in people with long-term diabetes [3]. Furthermore, subjects with diabetes have hippocampal and amygdala atrophy on brain imaging compared to nondiabetic subjects. The hippocampus and amygdala are responsible for such functions as memory and behavior and are also found to be atrophied in AD [4]. Postmortem studies of brains of diabetic individuals with dementia often reveal the coexistence of both brain microvascular lesions and extensive amyloid plaque burden, a characteristic of AD [5]. Additionally, numerous animal studies provided possible explanations for the putative link between diabetes and AD. Data from most animal studies found that insulin deficiency may result in $\mathrm{AD}$ pathology, including increased tau phosphorylation at multiple sites, increased tau cleavage and greater neuronal and synaptic damage, even with increased amyloid- $\beta$ peptide production $[6,7]$. However, $\mathrm{AD}$ pathology is more severe in type 2 diabetes mellitus animal models exhibiting hyperinsulinemia and insulin resistance [7].

With an aging population, the prevalence of diabetes and $\mathrm{AD}$ will continue to rise in the coming decades [8], thus posing a major public health problem. The findings from several cross-sectional studies suggest that diabetes and AD may be interrelated $[9,10]$. Several longitudinal studies have also found an association between a history of diabetes and dementia; however, these studies were limited by a relatively short follow-up period, a substantial loss of subjects to follow-up and/or a small sample size [11]. Hence, the purported link between diabetes and AD is yet to be confirmed by investigations controlling for the methodological problems in earlier studies. The objective of this study was to verify, using a large population-based cohort study design, the putative association between diabetes and the risk of AD.

\section{Materials and Methods}

\section{Data Sources}

The Department of Health in Taiwan reformed health insurance in 1995. By the end of 1996, around 96\% of the Taiwanese population had enrolled in the National Health Insurance (NHI) program [12], and the Bureau of National Health Insurance (BNHI) had contracted with $97 \%$ of hospitals and $90 \%$ of clinics [13]. To verify the accuracy of claim data, the BNHI performs quarterly expert reviews on a random sample of every 50-100 ambulatory and inpatient claims in each hospital and clinic. False reports of diagnoses result in a severe penalty from the BNHI. With ethical approval from the National Health Research Institutes, we obtained data for the current analysis from ambulatory care claims, all inpatient claims and the updated registry for beneficiaries from the years 2000-2008. With each individual personal identification number, all NHI datasets could be interlinked.

\section{Study Design, Cohorts and Comorbidities}

This was a population-based cohort study from 2000 to 2008 . Diabetic ambulatory care claim records included those patients coded with diabetes-related diagnoses, either International Classification of Disease, 9th Revision (ICD-9) code 250 or A-code A181. An individual was classified as being a diabetic patient if he or she had an initial diabetes-related diagnosis at any time in 2000 and was then diagnosed one or more times within the following 12 months. The first and last outpatient visits within 1 year were required to be $>30$ days apart to avoid accidental inclusion of miscoded patients [14]. To detect newly diagnosed AD, we excluded patients who sought treatment in hospitals or ambulatory care visits for AD (ICD-9 code 331.0) from 1997 to the first ambulatory care appearance in 2000 from our diabetic group. In total, 615,532 diabetic patients were identified in 2000. Control group subjects were selected from all beneficiaries insured in 2000 who did not have diabetes or AD between 1997 and 2000. A total of 614,871 age- and sex-matched control individuals were thus randomly selected.

Once the study subjects were identified, we searched the claims regarding ambulatory care visits and hospitalization for the selected comorbidities, including cerebrovascular disease (ICD-9 codes 430-432, 433-438), cardiovascular disease (ICD-9 codes 393-398, 410-414, 420-429, 440-449, 451-459; ICD-9 procedure codes 36.0, 36.01, 36.02, 36.05, 36.06, 36.1, 36.10-36.19, 391), hypertension (ICD-9 codes 401-405) and hyperlipidemia (ICD-9 codes 272.0-272.4). We counted these comorbidities only when the date of first-time diagnosis during the study period (2000-2008) was prior to the date of encountering the study endpoint (i.e. AD) or the date of censoring.

\section{Data Linkage and Statistical Analysis}

With the unique personal identification number, we linked study subjects in both diabetic and control groups to the claim data from 2000 to 2008 to identify the first occurrence of a primary or secondary diagnosis of AD. The index date for each study subject was the date of his/her first ambulatory care visit for diabetes in 2000. The date of encountering AD was the first day of ambulatory care or hospitalization with a primary or secondary diagnosis of AD following the index date. The study period was from 1 January 2000 to 31 December 2008, a 9-year period.

The geographic area of each member's NHI unit, either the location of employment or residential area, was grouped into 1 of 4 geographic areas (north, central, south or east) and 1 of 3 urbanization levels (metropolis, satellite city/town or rural) according to the National Statistics of Regional Standard Classification [15]. The age- and sex-specific incidence of AD was calculated with 
person-years as the denominator under the Poisson assumption. To assess the independent effects of diabetic status on the risk of $\mathrm{AD}$, Cox proportional hazards regression model analysis was performed, with adjustments for age, sex, insurance premium, selected comorbidities, geographic area and urbanization status. The latter two geographic variables were adjusted for possible geographic variations in health care accessibility and quality in Taiwan [16].

Subjects who died in hospital and did not have AD listed as one of the discharge diagnoses were censored in the survival analysis; the date of censorship was the date of death. If a study subject was not diagnosed with $\mathrm{AD}$ in an inpatient or outpatient setting, the date of censorship was either the date of their last withdrawal from NHI or the study end date. All statistical analyses were performed using SAS (version 9.1, SAS Institute, Cary, N.C., USA). A $\mathrm{p}$ value $<0.05$ was considered statistically significant.

\section{Results}

With the age- and sex-matched selection of control subjects, the age and sex distributions between the diabetic and control groups were very similar. The sample contained slightly more females (51.9\%) than males (48.1\%) and comprised approximately $40 \%$ elderly ( $\geq 65$ years) subjects in each group. The mean insurance premium was slightly lower in the diabetic group than in the control group. While there was no marked difference in living or working geographic areas between the two groups, diabetic patients tended to reside or work in urbanized regions. The prevalence rates of selected comorbidities, including cerebrovascular disease (48.6 vs. $30.4 \%$ ), cardiovascular disease (81.6 vs. $65.0 \%$ ), hypertension ( 89.6 vs. $62.1 \%)$ and hyperlipidemia (74.2 vs. $38.2 \%)$, were higher in the diabetic group compared with the control group (table 1).

Over nearly 9 years of follow-up, a total of 4,615 diabetic subjects developed $\mathrm{AD}$, representing a cumulative incidence rate of $0.75 \%$. The corresponding figure for control subjects was $0.63 \%(3,873 / 614,871)$. The overall incidence density was also higher in the diabetic group (0.99 per 1,000 patient-years) than in the control group (0.77 per 1,000 patient-years). Sex-stratified analysis revealed that women had a higher overall incidence of $A D$ than men, regardless of diabetic status (diabetic women/ men: $1.15 / 0.82$ per 1,000 patient-years; control women/ men: $0.89 / 0.63$ per 1,000 patient-years). The overall incidence of $\mathrm{AD}$ was higher in subjects aged $\geq 65$ years compared with subjects aged $<65$ years, regardless of sex or diabetic status. Diabetic women had the highest sex- and age-specific overall incidence of $\mathrm{AD}$ (2.47 per 1,000 person-years; table 2).
Table 1. Characteristics of the study subjects

\begin{tabular}{|c|c|c|c|c|}
\hline \multirow[t]{2}{*}{ Variable } & \multicolumn{2}{|c|}{ Control group } & \multicolumn{2}{|c|}{ Diabetic group } \\
\hline & $\mathrm{n}$ & $\%$ & $\mathrm{n}$ & $\%$ \\
\hline \multicolumn{5}{|l|}{ Age } \\
\hline$<65$ years & 366,427 & 59.6 & 366,967 & 59.6 \\
\hline$\geq 65$ years & 248,444 & 40.4 & 248,562 & 40.4 \\
\hline Mean age $\pm S D$, years & s $60.0 \pm 12.8$ & & $60.1 \pm 12.7$ & \\
\hline \multicolumn{5}{|l|}{ Sex } \\
\hline Male & 295,563 & 48.1 & 295,566 & 48.1 \\
\hline Female & 319,308 & 51.9 & 319,310 & 51.9 \\
\hline \multicolumn{5}{|l|}{ Insurance premium } \\
\hline Dependent & 156,296 & 25.4 & 169,761 & 27.6 \\
\hline \multicolumn{5}{|l|}{$<$ Median (NTD } \\
\hline 19,200$)$ & 135,948 & 22.1 & 137,408 & 22.3 \\
\hline$\geq$ Median & 322,627 & 52.5 & 308,363 & 50.1 \\
\hline \multicolumn{5}{|c|}{ Mean premium $\pm \mathrm{SD}^{1}$} \\
\hline NTD & $20,142.6 \pm 1$ & $5,269.4$ & $19,307.7 \pm 1$ & $4,454.7$ \\
\hline \multicolumn{5}{|l|}{ Geographic area } \\
\hline North & 269,239 & 44.2 & 269,920 & 44.4 \\
\hline Central & 151,693 & 25.0 & 141,321 & 23.2 \\
\hline South & 168,995 & 27.8 & 178,627 & 29.4 \\
\hline East & 17,938 & 3.0 & 17,944 & 3.0 \\
\hline \multicolumn{5}{|l|}{ Urbanization status } \\
\hline Metropolis & 243,808 & 39.8 & 255,467 & 42.0 \\
\hline Satellite city/town & 163,515 & 26.8 & 159,687 & 26.2 \\
\hline Rural area & 202,343 & 33.2 & 193,949 & 31.8 \\
\hline \multicolumn{5}{|l|}{ Comorbidities } \\
\hline \multicolumn{5}{|l|}{ Cerebrovascular disease } \\
\hline No & 428,246 & 69.6 & 316,627 & 51.4 \\
\hline Yes & 186,625 & 30.4 & 298,905 & 48.6 \\
\hline \multicolumn{5}{|c|}{ Cardiovascular disease } \\
\hline No & 215,104 & 35.0 & 113,509 & 18.4 \\
\hline Yes & 399,767 & 65.0 & 502,023 & 81.6 \\
\hline \multicolumn{5}{|l|}{ Hypertension } \\
\hline No & 233,171 & 37.9 & 80,400 & 13.1 \\
\hline Yes & 381,700 & 62.1 & 535,132 & 89.6 \\
\hline \multicolumn{5}{|l|}{ Hyperlipidemia } \\
\hline No & 379,843 & 61.8 & 158,950 & 25.8 \\
\hline Yes & 235,028 & 38.2 & 456,582 & 74.2 \\
\hline Total & 614,871 & 100.0 & 615,532 & 100.0 \\
\hline
\end{tabular}

Inconsistency between the total population and the population summed for individual variables was due to missing information. NTD = New Taiwan Dollars.

${ }^{1}$ The dependent insurers were not included.

After controlling for potential sociodemographic, geographic and clinical confounders, diabetic patients were found to have a significantly increased adjusted hazard ratio (AHR) of developing $\mathrm{AD}[1.45,95 \%$ confidence interval (CI) 1.38-1.52]. Women with diabetes had a 
Table 2. Overall and age- and sex-specific incidence densities and relative hazards of AD in the diabetic and control groups

\begin{tabular}{|c|c|c|c|c|c|c|c|c|}
\hline \multirow[t]{2}{*}{ Variable } & \multicolumn{3}{|c|}{ Control group } & \multicolumn{3}{|c|}{ Diabetic group } & \multirow{2}{*}{$\begin{array}{l}\text { HR in association } \\
\text { with diabetic group }\end{array}$} & \multirow{2}{*}{$\begin{array}{l}\text { AHR in association } \\
\text { with diabetic group }\end{array}$} \\
\hline & $\begin{array}{l}\text { number of } \\
\text { patients }\end{array}$ & $\begin{array}{l}\text { number } \\
\text { of events }\end{array}$ & $\begin{array}{l}\mathrm{ID}^{1} \text { per } 1,000 \\
\text { patient-years }\end{array}$ & $\begin{array}{l}\text { number of } \\
\text { patients }\end{array}$ & $\begin{array}{l}\text { number } \\
\text { of events }\end{array}$ & $\begin{array}{l}\mathrm{ID}^{1} \text { per } 1,000 \\
\text { patient-years }\end{array}$ & & \\
\hline \multicolumn{9}{|l|}{ Men } \\
\hline $\begin{array}{l}<65 \\
\text { years } \\
\geq 65\end{array}$ & 182,436 & 233 & $0.15(0.15-0.16)$ & 182,436 & 365 & $0.25(0.25-0.26)$ & $1.71(1.45-2.01)$ & $1.40(1.16-1.68)^{2}$ \\
\hline years & 113,127 & 1,270 & $1.53(1.52-1.53)$ & 113,129 & 1,433 & $1.92(1.92-1.93)$ & $1.28(1.19-1.38)$ & $1.41(1.30-1.53)^{2}$ \\
\hline Total & 295,563 & 1,503 & $0.63(0.62-0.63)$ & 295,566 & 1,798 & $0.82(0.81-0.82)$ & $1.31(1.22-1.41)$ & $1.40(1.30-1.51)^{3}$ \\
\hline \multicolumn{9}{|l|}{ Women } \\
\hline $\begin{array}{l}\text { years } \\
\geq 65\end{array}$ & 183,991 & 347 & $0.22(0.21-0.22)$ & 183,990 & 514 & $0.34(0.33-0.34)$ & $1.61(1.40-1.84)$ & $1.34(1.15-1.56)^{2}$ \\
\hline years & 135,317 & 2,023 & $1.91(1.91-1.92)$ & 135,318 & 2,303 & $2.47(2.46-2.47)$ & $1.32(1.25-1.41)$ & $1.52(1.42-1.62)^{2}$ \\
\hline Total & 319,308 & 2,370 & $0.89(0.88-0.89)$ & 319,310 & 2,817 & $1.15(1.15-1.16)$ & $1.31(1.24-1.39)$ & $1.48(1.39-1.57)^{3}$ \\
\hline Overall & 614,871 & 3,873 & $0.77(0.76-0.77)$ & 615,532 & 4,615 & $0.99(0.99-1.00)$ & $1.31(1.26-1.37)$ & $1.45(1.38-1.52)^{4}$ \\
\hline
\end{tabular}

Inconsistency between the total population and the population summed for individual variables was due to missing information. Figures in parentheses represent $95 \%$ CIs. ID = Incidence density.

${ }^{1}$ Based on the Poisson assumption. ${ }^{2}$ Based on Cox proportional hazards regression with adjustment for all variables, except for age and sex. ${ }^{3}$ Based on Cox proportional hazards regression with adjustment for all variables, except for sex. ${ }^{4}$ Based on Cox proportional hazards regression with adjustment for age, sex, insurance premium, geographic area, urbanization status, cerebrovascular disease, cardiovascular disease, hypertension, hyperlipidemia and diabetes status.

higher AHR (1.48, 95\% CI 1.39-1.57) than men with diabetes $(1.40,95 \%$ CI $1.30-1.51)$. While there was no difference in the age-specific AHR between elderly men and younger men, the AHR tended to be higher in elderly diabetic women (1.52, 95\% CI 1.42-1.62) compared with younger diabetic women (1.34, 95\% CI 1.15-1.56).

In addition to diabetes, certain sociodemographic and geographic factors and comorbidities were found to be associated with a significantly increased hazard for AD (table 3). Subjects aged $\geq 65$ years were 7 times more likely to develop AD than subjects aged $\leq 65$ years. Being female (AHR 1.31, 95\% CI 1.25-1.37) and having a higher insurance premium (AHR 1.25, 95\% CI 1.18-1.32) were also significantly $(\mathrm{p}<0.05)$ associated with an increased AHR for $\mathrm{AD}$. The AHR for $\mathrm{AD}$ varied with geographic location. Subjects who resided or worked in southern Taiwan had a higher AHR (1.92, 95\% CI 1.62-2.28) than subjects who resided or worked in eastern Taiwan (a relatively remote area). Cerebrovascular disease (AHR 1.74, 95\% CI 1.661.82), cardiovascular disease (AHR 1.09, 95\% CI 1.031.15) and hypertension (AHR 1.38, 95\% CI 1.30-1.48) were all associated with a significantly increased AHR for AD. Subjects with hyperlipidemia had a significantly reduced AHR for AD $(0.69,95 \%$ CI 0.66-0.72).

\section{Discussion}

The findings from our population-based study indicate that diabetes is associated with an increased risk of $\mathrm{AD}$. Older female diabetics tended to have the highest relative risk of developing $\mathrm{AD}$. The absolute risk of $\mathrm{AD}$ was found to be related to age in both diabetic and control subjects.

A common feature of $\mathrm{AD}$ and diabetes is amyloid deposition in target organs, namely amyloid- $\beta$ and tau in AD brains and amylin in pancreatic islets in type 2 diabetes [17]. Biochemical analysis supports a link between $\mathrm{AD}$ and insulin dysfunction [18]. An impaired insulin response in the brain [1], which may accelerate neurofibrillary tangle formation, has been proposed to increase the risk of $\mathrm{AD}$ in patients with diabetes [17]. In animal models, Takeda et al. [19] explored insulin action and its resistance in the development of cognitive impairment by cross-mating double transgenic models of AD and diabetes mellitus. They found that diabetes may accelerate the cerebrovascular inflammation but would not increase amyloid- $\beta$ levels. This report supports the notion that $\mathrm{AD}$ may be related to cerebrovascular dysfunction [20] and neuroinflammation [21]. It also supports our finding 
Table 3. Relative hazards of AD in relation to diabetes and various covariates

\begin{tabular}{|c|c|c|c|c|c|c|}
\hline Variable & $\begin{array}{l}\text { Number } \\
\text { of } \\
\text { patients }\end{array}$ & $\begin{array}{l}\text { Number } \\
\text { of } \\
\text { events }\end{array}$ & $\begin{array}{l}\text { Crude } \\
\text { HR }\end{array}$ & $95 \% \mathrm{CI}$ & $\mathrm{AHR}^{1}$ & $95 \% \mathrm{CI}$ \\
\hline \multicolumn{7}{|l|}{ Diabetes } \\
\hline No & 614,871 & 3,873 & 1.00 & & 1.00 & \\
\hline Yes & 615,532 & 4,615 & $1.31^{*}$ & $1.26-1.37$ & $1.45^{*}$ & $1.38-1.52$ \\
\hline \multicolumn{7}{|l|}{ Age } \\
\hline$<65$ years & 733,394 & 1,459 & 1.00 & & 1.00 & \\
\hline$\geq 65$ years & 497,006 & 7,029 & $8.58^{*}$ & $8.10-9.07$ & $7.49^{*}$ & $7.05-7.97$ \\
\hline \multicolumn{7}{|l|}{ Sex } \\
\hline Male & 591,129 & 3,301 & 1.00 & & 1.00 & \\
\hline Female & 638,618 & 5,187 & $1.40^{*}$ & $1.34-1.47$ & $1.31^{*}$ & $1.25-1.37$ \\
\hline \multicolumn{7}{|c|}{ Insurance premium } \\
\hline Dependent & 326,057 & 3,315 & $1.67^{*}$ & $1.58-1.77$ & $1.15^{*}$ & $1.08-1.23$ \\
\hline \multicolumn{7}{|l|}{$\begin{array}{l}<\text { Median } \\
\text { (NTD }\end{array}$} \\
\hline 19,200$)$ & 273,356 & 2,071 & $2.23^{*}$ & $2.12-2.34$ & $1.25^{*}$ & $1.18-1.32$ \\
\hline$\geq$ Median & 630,990 & 3,102 & 1.00 & & 1.00 & \\
\hline \multicolumn{7}{|c|}{ Geographic area } \\
\hline North & 539,159 & 4,005 & $1.75^{*}$ & $1.49-2.07$ & $1.86^{*}$ & $1.56-2.21$ \\
\hline Central & 293,014 & 1,710 & $1.39^{*}$ & $1.17-1.64$ & $1.47^{*}$ & $1.24-1.75$ \\
\hline South & 347,622 & 2,540 & $1.75^{*}$ & $1.48-2.07$ & $1.92^{*}$ & $1.62-2.28$ \\
\hline East & 35,882 & 146 & 1.00 & & 1.00 & \\
\hline \multicolumn{7}{|c|}{ Urbanization status } \\
\hline Metropolis & 499,275 & 3,679 & $1.10^{*}$ & $1.04-1.15$ & 1.03 & $0.97-1.10$ \\
\hline \multicolumn{7}{|l|}{ Satellite } \\
\hline city/town & 323,202 & 2,129 & 0.99 & $0.93-1.05$ & 0.91 & $0.85-0.97$ \\
\hline Rural area & 396,292 & 2,602 & 1.00 & & 1.00 & \\
\hline \multicolumn{7}{|c|}{ Comorbidities } \\
\hline \multicolumn{7}{|c|}{ Cerebrovascular disease } \\
\hline No & 744,873 & 3,256 & 1.00 & & 1.00 & \\
\hline Yes & 485,530 & 5,232 & $2.73^{*}$ & $2.62-2.86$ & $1.74^{*}$ & $1.66-1.82$ \\
\hline \multicolumn{7}{|c|}{ Cardiovascular disease } \\
\hline No & 328,613 & 1,721 & 1.00 & & 1.00 & \\
\hline Yes & 901,790 & 6,767 & $1.50^{*}$ & $1.42-1.58$ & $1.09^{*}$ & $1.03-1.15$ \\
\hline \multicolumn{7}{|c|}{ Hypertension } \\
\hline No & 313,571 & 1,373 & 1.00 & & 1.00 & \\
\hline Yes & 916,832 & 7,115 & $1.85^{*}$ & $1.75-1.96$ & $1.38^{*}$ & $1.30-1.48$ \\
\hline \multicolumn{7}{|c|}{ Hyperlipidemia } \\
\hline No & 538,793 & 4,022 & 1.00 & & 1.00 & \\
\hline Yes & 691,610 & 4,466 & $0.80^{*}$ & $0.76-0.83$ & $0.69^{*}$ & $0.66-0.72$ \\
\hline Total & $1,230,403$ & 8,488 & & & & \\
\hline
\end{tabular}

Inconsistency between the total population and the population summed for individual variables was due to missing information. ${ }^{*} \mathrm{p}<0.05$. NTD $=$ New Taiwan Dollars.

${ }^{1}$ Estimated from the Cox proportional hazards model with all variables listed in this table included in the regression equation.

that cerebrovascular disease, cardiovascular disease and hypertension were all significantly associated with an increased hazard of AD. Despite the existence of a plausible mechanism to explain the link between diabetes and $\mathrm{AD}$, controversy remains $[3,9,10]$, primarily because of a lack of large-scale epidemiology data to substantiate the pur- ported association. The findings from our large cohort study provide support for the proposed link between diabetes and AD. Specifically, our findings suggest that patients with diabetes are 1.45 times more likely than nondiabetics to develop AD. In addition, this relative risk estimate is similar to previous reported findings (1.3- to 2.4-fold increased risk) [22].

We also found that the absolute risk of AD increased with age in both diabetic and control subjects. It is well known that the incidence of $\mathrm{AD}$ increases exponentially with age to at least 90 years of age [23]. Age is a key risk factor for $\mathrm{AD}$ because the function of critical brain areas, such as the hippocampus, decreases with age [24]. Agingrelated atherosclerosis is also considered to contribute to the pathogenesis of AD [25]. As arteries stiffen and lymph drainage is impaired [26], the drainage of amyloid$\beta$ protein is also impaired, leading to deposition in the brain parenchyma and consequent AD [27]. Women had a slightly higher HR for AD compared to men. Gender is a well-established risk factor for AD, especially in older ages $[28,29]$. The overall relative risk estimate for $\mathrm{AD}$ in women subjects is comparable with that reported in earlier studies [29], suggesting that there is little ethnic variation with regards to the link between gender and AD.

Our study tended to suggest an effect modification with age on the relationship between diabetes and AD in women but not in men. Several studies have found an increased risk of $\mathrm{AD}$ in men with low serum levels of testosterone, which is the primary source of plasma estradiol in men. Because testicular secretion of testosterone never completely stops, serum estrogen levels are higher in elderly males than in postmenopausal women [30]. Additionally, insulin resistance and the compensatory hyperinsulinemia provoke increased androgen synthesis at the expense of decreased estrogen production [31]. Hence, while healthy premenopausal women enjoy the defensive effect of estrogens, older women with profound estrogen deficiency may have a higher risk of $\mathrm{AD}$. This may partly explain why there is no difference between older and younger men regarding the relative risk of $\mathrm{AD}$ and why older female diabetic patients have an increased risk of developing $\mathrm{AD}$ compared to nondiabetic women of a similar age.

Diabetes is a complex metabolic disorder which is closely associated with other vascular risk factors such as cerebrovascular disease [27], cardiovascular disease [32] and hypertension [33]. Vascular risk factors have been linked to the development of $\mathrm{AD}$ and contribute to the deposition of amyloid- $\beta$ protein in the brain [34]. Our results are consistent with previous findings that most vascular risk factors, except for hyperlipidemia, are asso- 
ciated with an increased risk of AD [8]. Results from epidemiologic studies examining the relationship between serum cholesterol levels and the risk of $\mathrm{AD}$ have been inconsistent [35-38]. The role of cholesterol as a susceptibility factor or a protective agent in neurodegeneration and, more generally, in amyloid-induced cytotoxicity remains controversial [39].

Unexpectedly, we noted an inverse association between hyperlipidemia and the risk of AD. There is still some debate regarding whether statins may reduce the risk of $\mathrm{AD}$ [40]. Based on a cross-sectional sample of nearly 5,000 elderly participants (355 cases of prevalent dementia, 200 with AD), Zandi et al. [41] found that statin use was inversely and significantly associated with the prevalence of dementia (adjusted odds ratio 0.44). After this sample was followed for 3 years, Zandi et al. [41] identified 185 cases of incident dementia (104 with AD) among 3,308 survivors at risk, and statin use at baseline did not significantly predict the incidence of dementia or AD (AHR for dementia and $\mathrm{AD}$ was 1.19 for both). Additionally, two recent randomized controlled trials also reported that statin had no benefit on the progression of symptoms in individuals with mild to moderate AD despite significant lowering of cholesterol $[42,43]$. On the other hand, The Rotterdam Study, a population-based study with some 7,000 participants and a mean of 9 years of follow-up, found that compared with no use of cholesterol-lowering drugs, statin use was associated with a decreased risk of AD (HR $0.57,95 \%$ CI $0.37-0.90$ ), but non-statin cholesterol-lowering drug use was not (HR 1.05, 95\% CI 0.45-2.44) [44].

In addition to cholesterol-lowering drugs, some medications used to treat diabetes were also found to be beneficial for neuropathological outcomes in $\mathrm{AD}$ patients. Beeri et al. [45] found that diabetic patients with concomitant use of both insulin and any oral antidiabetic medication had substantially lower neuritic plaque density. In a mouse model of AD, McClean et al. [46] demonstrated that liraglutide, a novel long-lasting incretin hormone glucagonlike peptide-1 analog, prevents key neurodegenerative developments found in AD. Recently, Hamilton et al. [47] used mouse models of diabetes to demonstrate that glucagon-like peptide-1 mimetics show promise as a treatment for neurodegenerative diseases such as $\mathrm{AD}$, because these novel drugs may cross the blood-brain barrier and increase neuroneogenesis. Due to a lack of prescriptions data available in our study, we are unable to assess whether or to what extent the medications used to treat diabetes or AD may have confounded the study findings.

In addition to demographic and clinical risk factors, we also noted that socioeconomic background was asso- ciated with the risk of AD. In keeping with findings from a previous report [48], we found that higher insurance premiums (and supposedly higher income) were associated with a lower risk of AD. Different lifestyle factors including education, occupation and leisure activities have been increasingly recognized as factors that may affect the development of AD [49]. The decreased risk of $\mathrm{AD}$ among individuals with better socioeconomic backgrounds might be related to a better brain reserve against brain damage [50].

We noted regional differences in the risk of AD. Specifically, diabetic subjects living or working in southern and northern Taiwan had higher relative risks of $\mathrm{AD}$ compared with their eastern and western counterparts. It is not clear what underlies such geographic variation in the risk of AD. Given that there is a higher density of medical centers in northern and southern Taiwan, the increased risk of $\mathrm{AD}$ in these areas may simply reflect the fact that the inhabitants have more ready access to medical consulting and are thus more likely to be diagnosed than inhabitants in other areas. Further studies are needed to examine this possibility.

Our study had several methodological strengths. Firstly, follow-up was based on the linkage of study subjects' personal identification numbers. This approach limited loss to follow-up. Response rates were also high, and recall bias was limited in the cohort studies. Secondly, the longitudinal records of a large sample of geographically dispersed patients were easily obtained because we used insurance claims data to obtain information. Including a large number of study subjects also allowed us to perform stratified analyses according to certain variables of interest such as age and sex.

There are several limitations to our study. Firstly, we were unable to differentiate between type 1 and type 2 diabetes. Given that only $1.8 \%$ of diabetics in Taiwan have type 1 diabetes [51], the majority of patients in our study likely had type 2 diabetes. Secondly, as NHI claim data were only available from 1997 onwards, we were not able to determine the exact duration of diabetes for each study patient, limiting our ability to assess the relationship between the timing of diabetes onset and AD. Thirdly, due to limited variables in the claim data, we were unable to adjust for a number of known clinical and environmental risk factors for $\mathrm{AD}$.

Determining whether there is a link between diabetes and $\mathrm{AD}$ is of great clinical and public health importance, as such information may provide crucial information for implementing $\mathrm{AD}$ prevention strategies, particularly in areas with aging populations such as Taiwan. Although 
the current study was based on a fairly large cohort, future studies should further remove potential confounding by known vascular and environmental risk factors for $\mathrm{AD}$ and determine the relationship between timing of diabetes onset and risk of AD in order to enhance evidence for the link between diabetes and AD. Our finding that elderly subjects with diabetes had a greater risk of $\mathrm{AD}$ suggests that older individuals with diabetes, who are vulnerable to $\mathrm{AD}$, should be treated aggressively.

\section{Conclusion}

The findings from our national population-based cohort study provide support for a link between diabetes and $\mathrm{AD}$, particularly in elderly women with diabetes. We suggest that diabetic patients should undergo routine mental and cognitive examinations to facilitate early detection and treatment of AD. Older diabetic women and their families should be made aware of the increased risk of $\mathrm{AD}$, and other risk factors for $\mathrm{AD}$ should be avoided as far as possible.

\section{Disclosure Statement}

This study was partially supported by a grant from the National Scientific Council (NSC98-2314-B-227-001-MY2). The interpretation and conclusions contained herein do not represent those of the BNHI, Department of Health or National Health Research Institutes. We also indicate that we do not have any conflict of interest regarding this study.

\section{References}

1 Schrijvers EM, Witteman JC, Sijbrands EJ, Hofman A, Koudstaal PJ, Breteler MM: Insulin metabolism and the risk of Alzheimer disease: the Rotterdam Study. Neurology 2010;75:1982-1987.

2 American Psychiatric Association: Diagnostic and Statistical Manual of Mental Disorders, ed 4 (DSM-IV). Washington, American Psychiatric Association, 1994.

-3 Arvanitakis Z, Wilson RS, Bienias JL, Evans DA, Bennett DA: Diabetes mellitus and risk of Alzheimer disease and decline in cognitive function. Arch Neurol 2004;61:661-666.

-4 den Heijer T, Vermeer SE, van Dijk EJ, Prins ND, Koudstaal PJ, Hofman A, Breteler MM: Type 2 diabetes and atrophy of medial temporal lobe structures on brain MRI. Diabetologia 2003;46:1604-1610.

5 Jellinger KA: The pathology of 'vascular dementia': a critical update. J Alzheimers Dis 2008; 14:107-123.

6 Qiu WQ, Folstein MF: Insulin, insulin-degrading enzyme and amyloid-beta peptide in Alzheimer's disease: review and hypothesis. Neurobiol Aging 2006;27:190-198.

7 Park SA: A common pathogenic mechanism linking type-2 diabetes and Alzheimer's disease: evidence from animal models. J Clin Neurol 2011;7:10-18.

$>8$ Zimmet P, Alberti KG, Shaw J: Global and societal implications of the diabetes epidemic. Nature 2001;414:782-787.

-9 Nielson KA, Nolan JH, Berchtold NC, Sandman CA, Mulnard RA, Cotman CW: Apolipoprotein-E genotyping of diabetic dementia patients: is diabetes rare in Alzheimer's disease? J Am Geriatr Soc 1996;44:897-904.
10 Janson J, Laedtke T, Parisi JE, O’Brien P, Petersen RC, Butler PC: Increased risk of type 2 diabetes in Alzheimer disease. Diabetes 2004;53:474-481.

11 Strachan MW, Deary IJ, Ewing FM, Frier BM: Is type II diabetes associated with an increased risk of cognitive dysfunction? A critical review of published studies. Diabetes Care 1997;20:438-445.

12 Lu JF, Hsiao WC: Does universal health insurance make health care unaffordable? Lessons from Taiwan. Health Aff (Millwood) 2003;22:77-88.

13 Chiang TL: Taiwan's 1995 health care reform. Health Policy 1997;39:225-239.

14 Chen HF, Ho CA, Li CY: Age and sex may significantly interact with diabetes on the risks of lower-extremity amputation and peripheral revascularization procedures: evidence from a cohort of a half-million diabetic patients. Diabetes Care 2006;29:2409-2414.

15 Directorate-General Budget, Accounting and Statistics: National Statistics of Regional Standard Classification Data. Taipei, Directorate-General Budget, Accounting and Statistics, 1993.

16 Chen HF, Ho CA, Li CY: Increased risks of hip fracture in diabetic patients of Taiwan: a population-based study. Diabetes Care 2008; 31:75-80.

17 Götz J, Streffer JR, David D, Schild A, Hoerndli F, Pennanen L, Kurosinski P, Chen F: Transgenic animal models of Alzheimer's disease and related disorders: histopathology, behavior and therapy. Mol Psychiatry 2004;9:664-683.

18 Gasparini L, Netzer WJ, Greengard P, Xu H: Does insulin dysfunction play a role in Alzheimer's disease? Trends Pharmacol Sci 2002;23:288-293.
19 Takeda S, Sato N, Uchio-Yamada K, Sawada K, Kunieda T, Takeuchi D, Kurinami H, Shinohara M, Rakugi H, Morishita R: Diabetesaccelerated memory dysfunction via cerebrovascular inflammation and Abeta deposition in an Alzheimer mouse model with diabetes. Proc Natl Acad Sci USA 2010;107: 7036-7041.

20 Iadecola C: Neurovascular regulation in the normal brain and in Alzheimer's disease. Nat Rev Neurosci 2004;5:347-360.

-21 Zhao WQ, Lacor PN, Chen H, Lambert MP, Quon MJ, Krafft GA, Klein WL: Insulin receptor dysfunction impairs cellular clearance of neurotoxic oligomeric $A \beta$. J Biol Chem 2009;284:18742-18753.

22 Biessels GJ, Staekenborg S, Brunner E, Brayne C, Scheltens P: Risk of dementia in diabetes mellitus: a systematic review. Lancet Neurol 2006;5:64-74.

23 Stern Y, Mayeux R, Sano M, Hauser WA, Bush T: Predictors of disease course in patients with probable Alzheimer's disease. Neurology 1987;37:1649-1653.

24 Ohnishi T, Matsuda H, Tabira T, Asada T, Uno M:Changesin brain morphologyin Alzheimer disease and normal aging: is Alzheimer disease an exaggerated aging process? AJNR Am J Neuroradiol 2001;22:1680-1685.

25 Dolan H, Crain B, Troncoso J, Resnick SM, Zonderman $\mathrm{AB}$, Obrien RJ: Atherosclerosis, dementia, and Alzheimer disease in the Baltimore Longitudinal Study of Aging cohort. Ann Neurol 2010;68:231-240.

26 Boche D, Zotova E, Weller RO, Love S, Neal JW, Pickering RM, Wilkinson D, Holmes C, Nicoll JA: Consequence of Abeta immunization on the vasculature of human Alzheimer's disease brain. Brain 2008;131:32993310. 
27 Weller RO, Yow HY, Preston SD, Mazanti I, Nicoll JA: Cerebrovascular disease is a major factor in the failure of elimination of Abeta from the aging human brain: implications for therapy of Alzheimer's disease. Ann NY Acad Sci 2002;977:162-168.

-28 Andersen K, Launer LJ, Dewey ME, Letenneur L, Ott A, Copeland JR, Dartigues JF, Kragh-Sorensen P, Baldereschi M, Brayne C, Lobo A, Martinez-Lage JM, Stijnen T, Hofman A: Gender differences in the incidence of $\mathrm{AD}$ and vascular dementia: the EURODEM Studies. EURODEM Incidence Research Group. Neurology 1999;53:1992-1997.

29 Hy LX, Keller DM: Prevalence of AD among whites: a summary by levels of severity. Neurology 2000;55:198-204.

-30 Janicki SC, Schupf N: Hormonal influences on cognition and risk for Alzheimer's disease. Curr Neurol Neurosci Rep 2010;10: 359-366.

31 Suba Z: Interplay between insulin resistance and estrogen deficiency as co-activators in carcinogenesis. Pathol Oncol Res 2011, Epub ahead of print.

- 32 Jefferson AL, Himali JJ, Beiser AS, Au R, Massaro JM, Seshadri S, Gona P, Salton CJ, DeCarli C, O’Donnell CJ, Benjamin EJ, Wolf PA, Manning WJ: Cardiac index is associated with brain aging: the Framingham Heart Study. Circulation 2010;122:690-697.

-33 Hassing LB, Hofer SM, Nilsson SE, Berg S, Pedersen NL, McClearn G, Johansson B: Comorbid type 2 diabetes mellitus and hypertension exacerbates cognitive decline: evidence from a longitudinal study. Age Ageing 2004;33:355-361.

34 Petrovitch H, White LR, Izmirilian G, Ross GW, Havlik RJ, Markesbery W, Nelson J, Davis DG, Hardman J, Foley DJ, Launer LJ: Midlife blood pressure and neuritic plaques, neurofibrillary tangles, and brain weight at death: the HAAS. Honolulu-Asia aging Study. Neurobiol Aging 2000;21:57-62.
5 Kivipelto M, Helkala EL, Laakso MP, Hänninen T, Hallikainen M, Alhainen K, Soininen $\mathrm{H}$, Tuomilehto J, Nissinen A: Midlife vascular risk factors and Alzheimer's disease in later life: longitudinal, population based study. BMJ 2001;322:1447-1451.

36 Whitmer RA, Sidney S, Selby J, Johnston SC, Yaffe K: Midlife cardiovascular risk factors and risk of dementia in late life. Neurology 2005;64:277-281.

37 Mielke MM, Zandi PP, Sjögren M, Gustafson D, Ostling S, Steen B, Skoog I: High total cholesterol levels in late life associated with a re duced risk of dementia. Neurology 2005;64: 1689-1695.

38 Mielke MM, Zandi PP, Shao H, Waern M, Östling S, Guo X, Björkelund C, Lissner L, Skoog I, Gustafson DR: The 32-year relationship between cholesterol and dementia from midlife to late life. Neurology 2010;75:18881895.

39 Stefani M, Liguri G: Cholesterol in Alzheimer's disease: unresolved questions. Curr Alzheimer Res 2009;6:15-29.

40 McGuinness B, Craig D, Bullock R, Passmore P: Statins for the prevention of dementia. Cochrane Database Syst Rev 2009; 2:CD003160.

41 Zandi PP, Sparks DL, Khachaturian AS, Tschanz J, Norton M, Steinberg M, WelshBohmer KA, Breitner JC; Cache County Study investigators: Do statins reduce risk of incident dementia and Alzheimer disease? The Cache County Study. Arch Gen Psychiatry 2005;62:217-224.

42 Sano M, Bell KL, Galasko D, Galvin JE, Thomas RG, van Dyck CH, Aisen PS: A randomized, double-blind, placebo-controlled trial of simvastatin to treat Alzheimer disease. Neurology 2011;77:556-563.

43 Feldman HH, Doody RS, Kivipelto M, Sparks DL, Waters DD, Jones RW, Schwam E, Schindler R, Hey-Hadavi J, DeMicco DA, Breazna A; LEADe Investigators: Randomized controlled trial of atorvastatin in mild to moderate Alzheimer disease: LEADe. Neurology 2010;74:956-964.
44 Haag MD, Hofman A, Koudstaal PJ, Stricker $\mathrm{BH}$, Breteler MM: Statins are associated with a reduced risk of Alzheimer disease regardless of lipophilicity. The Rotterdam Study. Neurol Neurosurg Psychiatry 2009;80:1317.

45 Beeri MS, Schmeidler J, Silverman JM, Gandy S, Wysocki M, Hannigan CM, Purohit DP, Lesser G, Grossman HT, Haroutunian V: Insulin in combination with other diabetes medication is associated with less Alzheimer neuropathology. Neurology 2008;71:750-757.

-46 McClean PL, Parthsarathy V, Faivre E, Hölscher C: The diabetes drug liraglutide prevents degenerative processes in a mouse model of Alzheimer's disease. J Neurosci 2011;31:6587-6594.

47 Hamilton A, Patterson S, Porter D, Gault VA, Holscher C: Novel GLP-1 mimetics developed to treat type 2 diabetes promote progenitor cell proliferation in the brain. J Neurosci Res 2011;89:481-489.

48 Stern Y: Cognitive reserve and Alzheimer disease. Alzheimer Dis Assoc Disord 2006; 20:S69-S74.

49 Amieva H, Jacqmin-Gadda H, Orgogozo JM, Le Carret N, Helmer C, Letenneur L, Barberger-Gateau P, Fabrigoule C, Dartigues JF: The 9 year cognitive decline before dementia of the Alzheimer type: a prospective population-based study. Brain 2005;128:1093-1101.

50 Katzman R: Education and the prevalence of dementia and Alzheimer's disease. Neurology 1993;43:13-20.

-51 Dasgupta K, Chan C, Da Costa D, Pilote L, De Civita M, Ross N, Strachan I, Sigal R, Joseph L: Walking behaviour and glycemic control in type 2 diabetes: seasonal and gender differences - study design and methods. Cardiovasc Diabetol 2007;6:1. 